\title{
Load-management applications for the industrial sector
}

\author{
S. Ashok*, R. Banerjee \\ Energy System Engineering, Indian Institute of Technology, Bombay, India
}

\begin{abstract}
The goal of any load-management program is to maintain, as nearly as possible, a constant level of load, thereby allowing the system load factor to approach $100 \%$. The important benefits of load management are reduction in maximum demand, reduction in power loss, better equipment utilisation and saving through reduced maximum demand charges. Load shifting, one of the simplest methods of load management, is to reduce customer demand during the peak period by shifting the use of appliances and equipment to partial peak and off-peak periods. Here no loads are being switched off, but only shifted or rescheduled, and hence the total production is not affected. In this paper, a fully fledged program is developed for load shifting and the same has been tried with the actual load data collected from a typical fertiliser and chemical industry plant.
\end{abstract}

Keywords: Load shifting; Peak demand; TOU rates

\section{Introduction}

Electrical energy is an essential ingredient for the industrial and all round development of any country. Electrical energy today constitutes about $30 \%$ of the total annual energy consumption on a world wide basis. This figure is expected to rise as oil supply for industrial uses becomes more stringent. As far as India is concerned, about $60 \%$ of the total power produced is consumed by industrial sector. The electricity requirement of India has grown tremendously and the demand has been running ahead of supply. With the present installed power capacity of about 88000 MW, India is facing an energy shortage of $12 \%$ with a peak deficit of 18 to $20 \%$. Within 10 years, a total peak demand of $200000 \mathrm{MW}$ is forecasted. To satisfy this demand, additional capacity is needed. But the cost involved for adding new generation 
capacity is about Rs. 5 crores per MW, besides the cost of transmission and distribution of about Rs. 4 crores per MW. This huge investment for the capacity addition and corresponding networks, forces the authorities and utilities look into various energy conservation and energy management programmes; hence the importance of load management (LM) as an energy-management technique, particularly in the industrial sector, to reduce the peak demand and energy requirements [2].

\section{Load management}

Load management $[1,6,7,12]$ is the process of scheduling the loads to reduce the electric energy consumption and or the maximum demand. It is basically optimizing the processes/loads to improve the system load factor. Load-management procedures involve changes to equipment and/or consumption patterns on the customer side. There are many methods of load management which can be followed by an industry or a utility, such as load shedding and restoring, load shifting, power wheeling, installing energy-efficient processes and equipment, energy storage devices, co-generation and non-conventional sources of energy, and reactive power-control [3].

Meeting the peak demand is one of the major problems now facing the electric utilities. With the existing generating capacity being unmanageable, authorities are forced to implement load shedding in various sectors during most of the seasons. Load shifting will be a better option for most industries. Load shifting basically means scheduling the load in such a way that loads are diverted from peak period to off-peak periods, thereby shaving the peak and filling the valley of the load curve, so improving the load factor.

To encourage load shifting in industries, and thereby to reduce peak demand, many utilities have already implemented time of use rates (TOU) or have plans for introducing such rates [12].

\section{Load shifting}

This can be considered to be a better and simpler method of load management because it does not change the total production output and is easy to implement. In this technique, the total processes (loads) are rescheduled, and not switched off, in such a way to reduce the peak demand and improve the load factor. It is not possible to reschedule all the processes or shift certain types of loads. So the load-shifting technique has to select the loads which can be shifted or processes which can be rescheduled. Constraints like interlocked processes and storage-space limitations will have to be studied in detail before implementing the techniques.

\subsection{Methodology of load shifting}

This is the use of economic incentives and disincentives offered through the electric rate structure to encourage voluntary changes in customer consumption-patterns. 
Under the load-shifting method, electric power to all loads is always available, but the rate may vary with the time of day or use (TOU) and depend on the power demand as well as total energy consumed [11]. The aim of the load-shifting method is to reduce customer demands during peak periods by shifting the use of appliances and equipment to off-peak/partial peak periods. The rates used with the load-shifting method may also encourage new loads to occur during the off-peak period. No inconvenience or discomfort results from the load-shifting method, though there may be economic penalties resulting from excessive peak-period electricity use $[8,9]$.

\subsection{Load or process constraints}

In industries, there will be a large number of processes (loads). Sometimes it is not possible to shift a particular load alone from one interval to another. For example, a particular process may be inter-locked with other processes. Or sometimes, certain loads or processes are continuous. Thus, loads having process interconnections or loads in a continuous process chain cannot be controlled independently. These loads will have to be controlled together. In certain cases, in between two process there may be a storage space. The limitations of the storage space will result in a storage constraint.

\subsubsection{Interlocked processes}

In the example shown in Fig. 1, two loads, $\mathrm{L}_{1}$ the conveyer and $\mathrm{L}_{2}$ the heater and crusher processes of a fertilizer and chemical plant, are shown. The conveyor is loading the heater and crusher. Being continuous, these two loads are interlocked and cannot be controlled independently. For any LM program, both loads will have to be controlled together. We cannot shift process $\mathrm{L}_{1}$ or $\mathrm{L}_{2}$ independently. If required, we have to shift these two processes together.

\subsubsection{Storage-space constraint}

Industries may have a number of storage spaces with loads associated with them (for example, see Fig. 2). The raw water pump $\mathrm{L}_{5}$ is pumping water from a river to the storage tank $(\mathrm{S})$. After treatment of the water inside the tank, it is pumped out by the treated water pump $\mathrm{L}_{10}$.

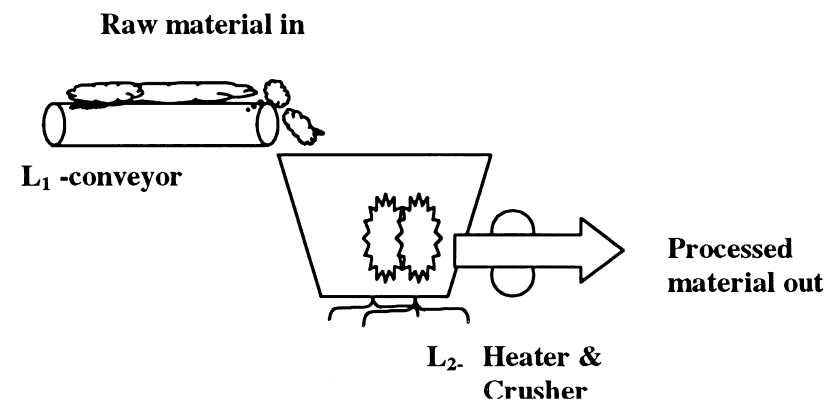

Fig. 1. Interlocked process. 


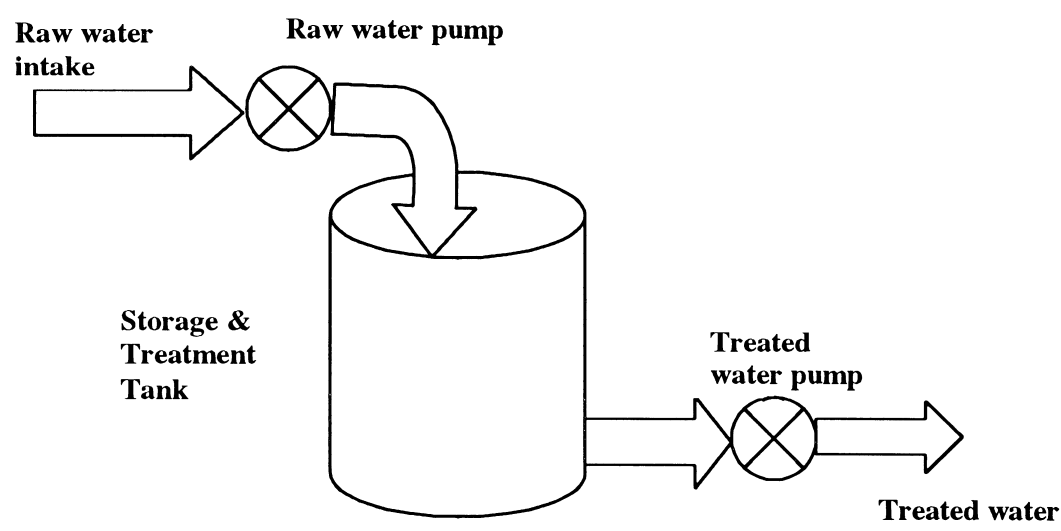

Fig. 2. Storage space constraint.

We cannot control these processes (pump loads) independently without considering the storage capacity of the storage space (S units). Pump $\mathrm{L}_{5}$ has to stop whenever the water upper limit is reached in the tank. Similarly, there are several constraints for the operation of the pumps. Hence we have to control or shift the processes $\mathrm{L}_{1}$ and $\mathrm{L}_{2}$ by considering the capacity of the storage space ( $\mathrm{S}$ units) as well as the pump flow (discharge and suction) rates.

\section{Implemantation and results}

The load-shifting technique is applied to a typical fertilizer and chemical industry plant in Cochin, Kerala, India [11]. This plant is selected because (1) the processes are energy-intensive and (2) the plant is supplied by Kerala Grid, where TOU rates have been implemented. Load data have been collected from the industry on a normal shift day. For simplicity, the load data are taken only for every hour. The total connected load of the plant is $24.7 \mathrm{MW}$, and is composed of 12 independent process-plant loads, with details shown below. The contract maximum demand (CMD) is $21.5 \mathrm{MW}$ :

Primary treatment plant

Heater and crusher

Raw water pumping station

Oxide plant

Chemical inspection and lab Lighting

$$
\begin{array}{ll}
\mathrm{L}_{1}=2000 \mathrm{~kW}, & \text { Conveyor } \\
\mathrm{L}_{3}=500 \mathrm{~kW}, & \text { Nitrogen plant } \\
\mathrm{L}_{5}=4250 \mathrm{~kW}, & \text { Ammonia processor } \\
\mathrm{L}_{7}=1300 \mathrm{~kW}, & \text { Acid plant } \\
\mathrm{L}_{9}=750 \mathrm{~kW}, & \text { Treated water pump load } \\
\mathrm{L}_{11}=250 \mathrm{~kW}, & \text { Urea plant }
\end{array}
$$

$$
\begin{aligned}
& \mathrm{L}_{2}=100 \mathrm{~kW}, \\
& \mathrm{~L}_{4}=1925 \mathrm{~kW}, \\
& \mathrm{~L}_{6}=2100 \mathrm{~kW}, \\
& \mathrm{~L}_{8}=1000 \mathrm{~kW}, \\
& \mathrm{~L}_{10}=5000 \mathrm{~kW}, \\
& \mathrm{~L}_{12}=4525 \mathrm{~kW} .
\end{aligned}
$$

For simplicity, we have not considered the individual loads of the equipment in each plant separately. Most of the individual loads of each plant are interconnected, so giving less chance for load-shifting independently. The costs of the total electrical energy before shifting and after shifting are calculated with the TOU tariff rate applying by the Kerala grid [10]. The tariff for the industrial sector is as follows: 
$\begin{array}{lll}\text { Flat rates: } & \text { Demand charge: } & \text { Rs. } 133 / \mathrm{kVA} \\ & \text { Energy charge: } & \text { Rs. } 1.22 \text { per unit } \\ & \text { (Note: present transaction rate } 1 \mathrm{US} \$ \cong \mathrm{Rs} .42 .0) \\ \text { TOU rates: } & \text { Energy charges: } & \text { partial peak } 6 \text { am-6 pm: flat rate (normal) } \\ & & \text { peak period } 6 \text { pm-10 pm: double } \\ & & \text { Off peak } 10 \mathrm{pm}-6 \mathrm{am} \text { : quarter }\end{array}$

Steps in the load shifting algorithm made are as follows:

1. Read the load data at different time instants; contract maximum-demand (CMD) or any preferred maximum-demand limit (PMD), TOU rates, 'not possible' loads for shifting with their time intervals and constraints.

2. Calculate the maximum demand (MD) at each time instant and cost of electricity for the day.

3. IF MD $\supseteq$ CMD or PMD, find all the loads (excluding those 'not possible' for the instant for shifting) 'on' and select the smallest.

4. Check for constraints:

4.1. if interlocked, select all the interlocked loads together

4.2. if storage constrained, see the constraints and follow.

5. Shift the loads to other intervals where MD $<$ PMD. Calculate new MD and cost of electricity for the day with new load data.

6. Do the steps for all possible loads and for all the time instants in a repetitive manner such that $\Sigma$ (cost of electrical energy for the day) is a minimum.

Here, 'not possible' loads for a time period indicate loads which cannot be shifted from that period to any other period, e.g. lighting load. As already said, the loads $\mathrm{L}_{2}$ and $\mathrm{L}_{3}$ are interlocked. The conveyor is feeding the raw material to the heatercrusher. We have to shift these two processes simultaneously only if required. $\mathrm{L}_{5}$ and $\mathrm{L}_{10}$ are considered to be storage space constraints with control as follows:

start $\mathrm{L}_{5} \quad$ (1) whenever water level $=\mathrm{L}_{\text {min }}$ provided $\mathrm{L}_{10}$ is on

(2) when water level is $<\mathrm{L}_{\max }$ and period is not peak

stop $\mathrm{L}_{5} \quad$ (1) whenever water level is $=\mathrm{L}_{\max }$

operate $\mathrm{L}_{10} \quad$ whenever water level is $>\mathrm{L}_{\min }$ and the period is not a peak, for a total time period of $T \mathrm{~h} /$ day sufficient for filling the treated water tank for the day's requirement.

Results of the load-shifting implementation are given in Table 1.

Table 1

Results for load-shifting technique [4,5]

\begin{tabular}{|c|c|c|c|c|c|c|c|}
\hline \multicolumn{4}{|c|}{ Before shifting } & \multicolumn{4}{|c|}{ After shifting } \\
\hline \multirow[b]{2}{*}{$\begin{array}{l}\text { Maximum } \\
\text { demand }\end{array}$} & \multirow[b]{2}{*}{$\begin{array}{l}\text { Total } \\
\text { energy }\end{array}$} & \multicolumn{2}{|c|}{ Total electricity cost } & \multirow[b]{2}{*}{$\begin{array}{l}\text { Maximum } \\
\text { demand }\end{array}$} & \multirow[b]{2}{*}{$\begin{array}{l}\text { Total } \\
\text { energy }\end{array}$} & \multicolumn{2}{|c|}{ Total electricity cost } \\
\hline & & $\begin{array}{l}\text { With flat } \\
\text { rate (Rs.) }\end{array}$ & $\begin{array}{l}\text { With TOU } \\
\text { rate (Rs.) }\end{array}$ & & & $\begin{array}{l}\text { With flat } \\
\text { rate (Rs.) }\end{array}$ & $\begin{array}{l}\text { With TOU } \\
\text { rate (Rs.) }\end{array}$ \\
\hline $23.7 \mathrm{MW}$ & $517.4 \mathrm{MWh}$ & $3,783,328$ & $3,841,354$ & $22.85 \mathrm{MW}$ & $517.4 \mathrm{MWh}$ & $3,670,278$ & $3,734,068$ \\
\hline
\end{tabular}




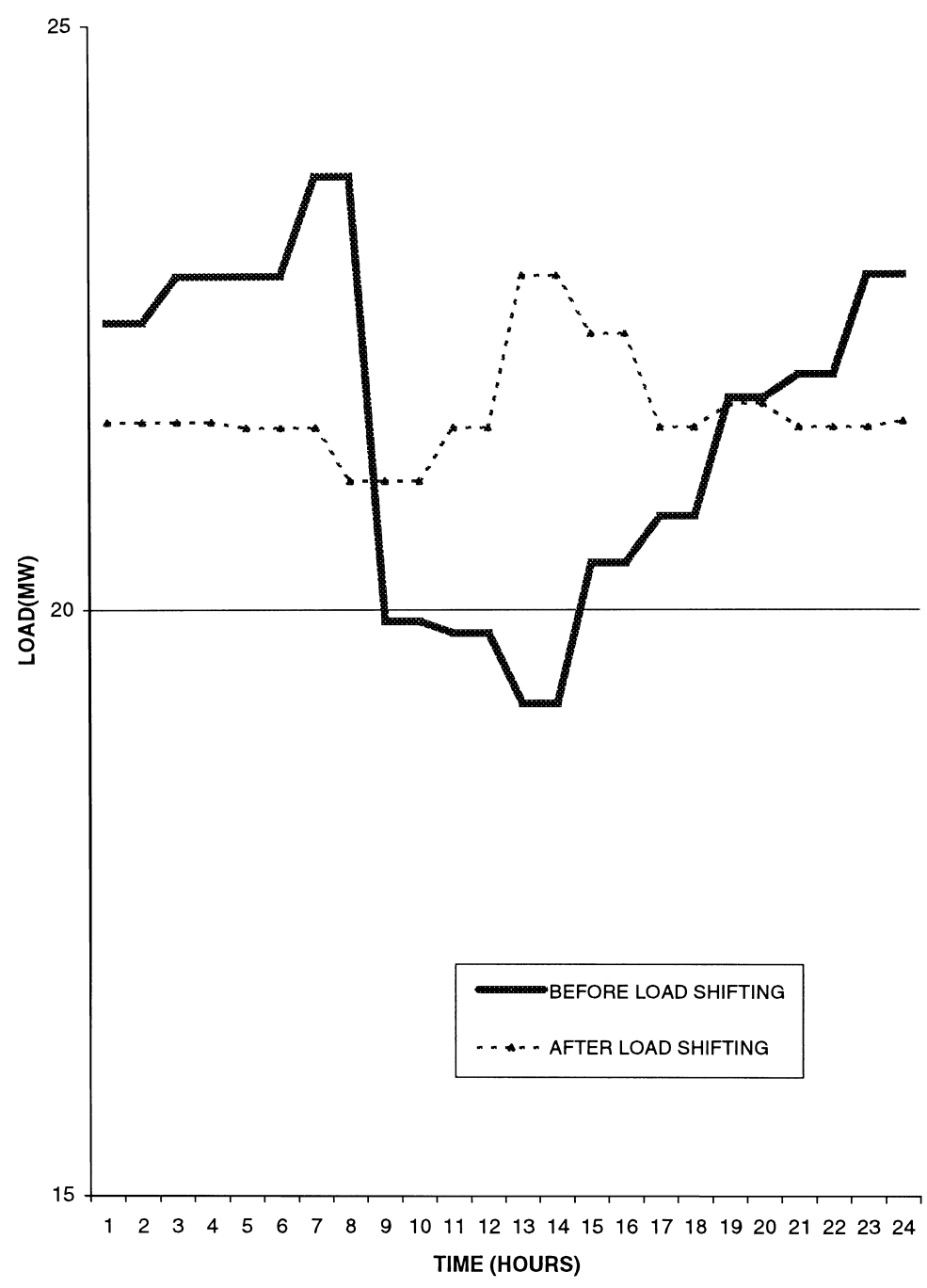

Fig. 3. Load curves.

The daily load curves for the industry before and after load shifting are shown in Fig. 3. By applying the LM program, the load factor is improved by $4.5 \%$. The reduction in peak demand is $0.85 \mathrm{MW}$, thereby saving electricity costs by Rs. 107286 for 1 day.

\section{Conclusion}

It is shown that by implementing the load-shifting technique, the maximum demand can be reduced and hence the load factor can be improved. Reducing the 
peak demand will reduce the electricity cost for the industries especially with the TOU tariffs. Utilities will get a relief as the peak of the load curve is flattened. Loadshifting techniques will be a better method for load management programs in industries, because they do not change the total production output and are easier to implement. The application of the load-shifting technique to a typical energy intensive industry reveals the scope of the program for the industrial sector.

\section{References}

[1] Bjork CO. Industrial load management — theory practice \& simulation. New York: Elsevier, 1989.

[2] Parikh JK, Reddy BS, Banerjee R. Planning for demand side management in the electricity sector. New Delhi: Tata McGraw-Hill, 1994.

[3] Cochen AI, Wang CC. An optimisation method for load management scheduling. IEEE Transactions on Power Systems 1988;3(2):612-8.

[4] Bhagwan Das D, Patvardhan C. Solution of economic load dispatch using real coded hybrid stochastic search. Electrical Power and Energy Systems 1998;21(3):165-70.

[5] Chirattananon $\mathrm{S}$ et al. A model for the performance evaluation of the operation of EAF. Energy Coserv Mgmt 1996;37:161-6.

[6] Vogt LJ, Conner DA. Electrical energy management. Toronto: Lexington Books, 1977.

[7] Isaksen, L, Ma, FS, and Simons, NW. Bibliography and load management. IEEE Transactions on Power Apparatus and Systems 1981: PAS-100(5):1981.

[8] Nagarath, IJ, Kothari, DP. Modern power system engineering. Tata McGraw-Hill, 1995.

[9] Wood J, Wollenberg BF. Power generation, operation and control. New York: John Wiley and Sons, 1983.

[10] KSEB Engineers Journal, HYDEL 1996:42(1).

[11] Bharanam V. Objectivity linked microlevel budget of Kerala State Electricity Board (India). Trivandrum, Kerala: KSEB, 1996.

[12] Sheen JN et al. TOU pricing of electricity for load management in Taiwan power company. IEEE Trans on Power Systems 1994;9:388-96. 